\title{
2005 Update for Implementing Best Available Technology Per DOE Order 5400.5
}

Michael G. Lewis

September 2006

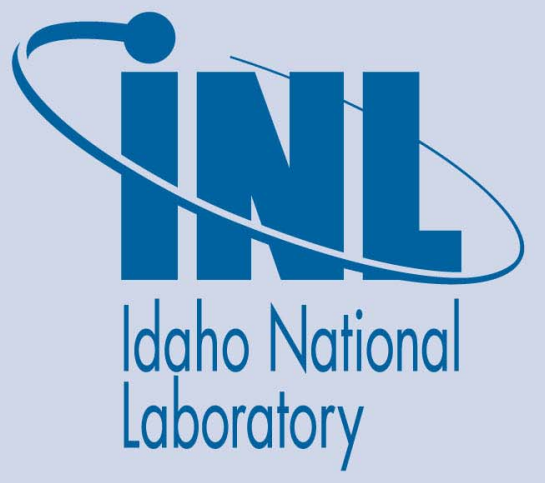

The INL is a U.S. Department of Energy National Laboratory operated by Battelle Energy Alliance 
INL/EXT-06-11609

\title{
2005 Update for Implementing Best Available Technology Per DOE Order $\mathbf{5 4 0 0 . 5}$
}

Michael G. Lewis

September 2006

\author{
Idaho National Laboratory \\ Idaho Falls, Idaho 83415
}

Prepared for the

U.S. Department of Energy

Under DOE Idaho Operations Office

Contract DE-AC07-05ID14517 


\begin{abstract}
In accordance with Contract Data Requirements List F.19, this report addresses the Best Available Technology requirements per Department of Energy (DOE) Order 5400.5, "Radiation Protection of the Public and the Environment," as they apply to radiological discharges to the soil for Calendar Year 2005. The report includes review of discharges for both, Battelle Energy Alliance, LLC and CH2M-WG Idaho, LLC.

The Best Available Technology selection process is applicable to wastewater discharges containing process derived radionuclides to surface waters, sanitary sewerages greater than five times the Derived Concentration Guideline (found in DOE Order 5400.5), and to the soil. Wastewater at the Idaho National Laboratory Site is not discharged to surface water (Big Lost River and Birch Creek) nor is it discharged to sanitary sewerages at activity levels greater than five times a Derived Concentration Guideline. Therefore, this report focuses on radiological discharges to the soil.
\end{abstract}





\section{CONTENTS}

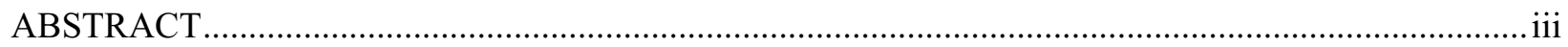

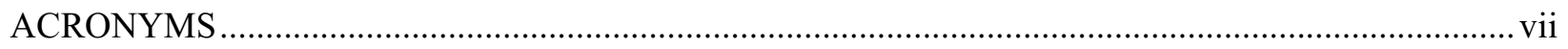

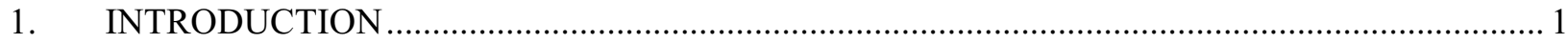

2. COMPLIANCE WITH BEST AVAILABLE TECHNOLOGY REQUIREMENTS ...................... 2

3. CALENDAR YEAR 2005 WASTEWATER DISCHARGES TO THE SOIL ............................... 3

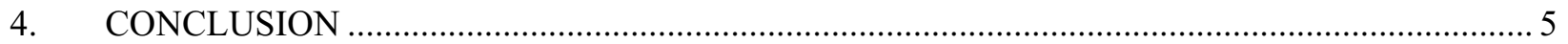

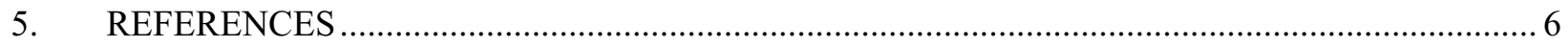





\section{ACRONYMS}

BAT best available technology

BEA Battelle Energy Alliance, LLC

CWI CH2M-WG Idaho, LLC

DCG Derived Concentration Guide

DOE Department of Energy

DOE-ID Department of Energy Idaho Operations Office

EMIS Environmental Information System

EMPP Environmental Monitoring Program Plan

ICS interim control strategy

INL Idaho National Laboratory

IWTS Integrated Waste Tracking System

MCL maximum contaminant level

MFC Materials and Fuels Complex

MDA minimum detectable activity

$\mathrm{pCi} / \mathrm{L} \quad$ picocuries per liter

PLN plan

STF Sewage Treatment Facility

TAN Test Area North

TSF Technical Support Facility

WDDF Waste Determination and Disposition Form

WGS Waste Generator Services

WLAF wastewater land application facility 


\section{Update for Implementing Best Available Technology per DOE Order $\mathbf{5 4 0 0 . 5}$}

\section{INTRODUCTION}

In accordance with Contract Data Requirements List F.19, this report addresses the Best Available Technology (BAT) requirements per Department of Energy (DOE) Order 5400.5, "Radiation Protection of the Public and the Environment," and radiological discharges to the soil for Calendar Year 2005. The report includes review of discharges for both, Battelle Energy Alliance, LLC (BEA) and CH2M-WG Idaho, LLC (CWI).

The best available technology selection process is conducted according to DOE Order 5400.5, Chapter II, Section 3, "Management and Control of Radioactive Materials in Liquid Discharges and Phaseout of Soil Columns," and DOE guidance. " Typically, selection of BAT for a specific application is made from among candidate alternative treatment technologies. Those alternative treatment technologies are identified by an evaluation process according to DOE Order 5400.5, Chapter II, Section 3.a.(1)(a). The evaluation process includes factors related to technology, economics, and public policy considerations.

The BAT selection process is applicable to wastewater discharges to surface waters [DOE Order 5400.5, Chapter II, Section 3.a.(1)] that contain radioactivity levels above DOE Order 5400.5 Derived Concentration Guidelines (DCGs) or discharges to sanitary sewerages greater than five times the DCGs. During Calendar Year 2005, wastewater at the Idaho National Laboratory (INL) Site was not discharged to the Big Lost River, Little Lost River, or Birch Creek and there were no discharges to sanitary sewerages greater than five times the DCGs.

The BAT selection process is also applicable to liquid waste streams that will continue to be discharged to soil columns for indefinite periods and that contain process-derived radionuclides [DOE Order 5400.5, Chapter II, Section 3.b.(1)]. DOE Headquarters provided additional guidance ${ }^{\mathrm{a}}$ (ref. Section 2) for determining what is considered a discharge to a soil column. This guidance, as well as DOE Order 5400.5 requirements were incorporated into the INL Site plan (PLN)-932 "Management Plan and Implementation of Best Available Technology per DOE Order 5400.5 for Disposal of Wastewater." Following PLN-932 insures compliance with DOE Order 5400.5 and DOE Headquarters guidance. PLN-932 was used by both BEA and CWI during Calendar Year 2005 to characterize wastewater prior to discharge to the soil. For BEA, PLN-932 was revised on July 18, 2006 to reflect only BEA operated facilities. The BEA plan is now PLN-8104 "Management Plan and Implementation of Best Available Technology per DOE Order 5400.5 for Disposal of Wastewater." CWI continues to follow PLN-932.

a. James R. Cooper, DOE-ID, e-mail to Brett R. Bowhan, R. M. Kauffman, etc., "Perc Pond Update," February 5, 2001, 10:38 a.m., CCN 35553. 


\section{COMPLIANCE WITH BEST AVAILABLE TECHNOLOGY REQUIREMENTS}

With the exception of the Materials and Fuels Complex (MFC), PLN-932 is a self-implementing screening tool that establishes radiological release levels for disposal of purged well water to the ground surface, and other wastewaters to wastewater land application facilities or directly to the ground surface. PLN-932 requires that wastewater containing radiological contaminants must be evaluated to ensure compliance with DOE Order 5400.5. The BAT selection process, as required by DOE Order 5400.5, applies to "wastewater that will continue to be discharged to soil columns for indefinite periods and that contain process-derived radionuclides."

For the purposes of this screening tool, if wastewater is below current drinking water maximum contaminant levels (MCLs) for radionuclides, then the goals of the BAT selection process have been met and the wastewater is considered clean water (from a radiological standpoint). Therefore, discharges of these wastewaters to the ground surface do not constitute discharge to a soil column. Adherence to the recommendations in PLN-932 is appropriate documentation of the BAT selection process and compliance with DOE Order 5400.5. PLN-932 describes how to determine if radionuclide levels in wastewater are at or below the MCLs

For wastewater with radioactivity above MCLs, but below one DCG, the wastewater is considered acceptable for discharge to the soil provided the BAT selection process has been completed. Typically, selection of BAT for a specific application will be made from among candidate alternative treatment technologies, which are identified by an evaluation process in accordance with DOE Order 5400.5, Chapter II, Section 3.a.(1)(a) that includes factors related to technology, economics, and public policy considerations. The BAT plan must be submitted to the DOE Field Office Manager for approval. The BAT plan must be revised annually and resubmitted to the DOE Field Office Manager for approval.

Wastewater with radiological activity levels above DCGs may not be disposed of to the soil. Alternative disposal methods must be used for these wastewaters.

As discussed in PLN-932, wastewaters containing radiological contaminants generated by the MFC were managed in accordance with the MFC Environmental Monitoring Program Plan (EMPP) approved by DOE-Chicago. The MFC EMPP allowed discharge of radionuclides in wastewater to the soil at activity levels up to DCGs. Although a higher radioactivity release level was allowed in the wastewater, information provided by MFC facility personnel indicated that no wastewater was intentionally discharged to the soil in concentrations greater than MCLs during 2005. 


\title{
3. CALENDAR YEAR 2005
}

\section{WASTEWATER DISCHARGES TO THE SOIL}

\begin{abstract}
Although PLN-932 is self-implementing for releases below MCLs, users may seek assistance in determining wastewater disposal options from Waste Generator Services (WGS) and/or the appropriate environmental personnel. Nonroutine releases to the ground surface or to wastewater land application facilities (WLAFs) must be approved by the applicable facility manager prior to disposal. In order to maintain records of these specific releases, the project manager shall submit release information to WGS as required by WGS operating procedures. A Waste Determination and Disposition Form (WDDF) (Form 435.39) will be provided by WGS for this purpose. As required by WGS procedures, release information will be tracked in the WGS Integrated Waste Tracking System (IWTS). Monitoring or production-well purge water releases consisting of groundwater known to be uncontaminated or contaminated below MCLs are exempt from the approval requirements.
\end{abstract}

A review of the WGS information for Calendar Year 2005 did not identify any records showing wastewater discharges to the soil exceeding MCLs. There were no BAT plans developed by BEA or CWI that were submitted to the DOE Idaho Operations Office (DOE-ID) in 2005.

In addition, effluent radiological data from the Environmental Monitoring Information System (EMIS) for Calendar Year 2005 was reviewed for the following WLAFs:

- $\quad$ Central Facilities Area Sewage Treatment Plant

- Idaho Nuclear Technology and Engineering Center New Percolation Ponds

- $\quad$ MFC Industrial Waste Ditch

- $\quad$ MFC Industrial Waste Pond

- $\quad$ Reactor Technology Complex Cold Waste Pond

- $\quad$ Test Area North/Technical Support Facility (TAN/TSF) Sewage Treatment Facility (STF) Disposal Pond

All radioactivity levels ${ }^{\mathrm{b}}$, with the exception of radium-226 (Ra-226) in the effluent to the MFC Industrial Waste Ditch and strontium-90 (Sr-90) in the effluent to the TAN/TSF STF Disposal Pond, were reported as undetected or below MCLs. In addition, the majority of the radionuclides that were analyzed were below the laboratories instrument detection level.

Ra-226 was detected above its respective MCL $(5 \mathrm{pCi} / \mathrm{L})$ in one sample collected from effluent to the MFC Industrial Waste Ditch. The sample collected on April 27, 2005, measured 6.04+/-2.75 pCi/L for Ra-226. The sample result was qualified "J," indicating the sample result is greater than the 2 sigma $(2 \mathrm{~S})$ uncertainty but less than 3 times $(3 \mathrm{~S})$ the uncertainty and above the laboratory minimum detectable activity (MDA) of $5.81 \mathrm{pCi} / \mathrm{L}$. The sample result was only slightly higher than the instruments MDA and the MCL for Ra-226. Subsequent samples collected during Calendar Year 2005 were undetectable for Ra-226. It is possible that the one time detection was an anomaly associated with the analysis.

\footnotetext{
${ }^{\mathrm{b}}$ Radiological data obtained from the EMIS.
} 
In a sample collected on March 17, 2005 from the effluent to the TAN/TSF STF Disposal Pond, Sr90 exceeded the MCL of $8 \mathrm{pCi} / \mathrm{L}$. The activity level in this sample was $14.4 \mathrm{pCi} / \mathrm{L}$. Subsequent samples collected in 2005 showed Sr-90 levels below the MCL. In the past, Sr-90 levels above the MCL have occasionally been detected in the effluent to the TAN/TSF STF Disposal Pond. To support continued discharge to the Disposal Pond, an Interim Control Strategy (ICS) was initially prepared in 2003 and submitted to DOE-ID pursuant to DOE Order 5400.5, Chapter II, Section 3.e.(1). The ICS is required to be updated and resubmitted every two years and was therefore, resubmitted in April 2005. The ICS was prepared to address DOE Order 5400.5, Chapter II, Section 3.b.(1), which states: "The use of soil columns (i.e., trenches, cribs, ponds, and drain fields) to retain, by sorption or ion exchange, suspended or dissolved radionuclides from liquid waste streams shall be discontinued at the earliest practicable time in favor of an acceptable alternative disposal means" and DOE Order 5400.5, Chapter II, Section 3.c.(2), which states: "Liquid discharges, even though uncontaminated, are prohibited in inactive release areas to prevent the further spread of radionuclides previously deposited."

In the 2005 ICS update, two possible pathways for the Sr-90 elevated levels were identified. One possible pathway is from residues from past practices. Elevated levels of Sr-90 were detected in sediments of the TAN/TSF STF collection system manholes and sumps during a sampling event in May 2004. Activity levels as high as $262 \mathrm{pCi} / \mathrm{L}$ were detected in one of the manholes.

The second potential pathway identified was soil from recent remediation work, which may have entered into the system. During remediation activities, water was sprayed onto disturbed soils for the purpose of dust suppression and this soil could have been washed into the TAN/TSF STF collection system. It is also possible that storm water could have washed this soil into the TAN/TSF STF collection system. 


\section{CONCLUSION}

Both BEA and CWI used PLN-932 during Calendar Year 2005 to determine wastewater disposal paths. Following PLN-932 ensures that wastewater is disposed of in compliance with the DOE Order 5400.5 BAT requirements. A review of the 2005 WGS waste disposal records did not show any discharges to the soil with radioactivity levels greater than MCLs.

With the exception of the MFC Industrial Waste Ditch and the TAN/TSF STF Disposal Pond, radiological data from effluent sampling activities at the WLAFs did not show radioactivity levels above MCLs. Ra-226 was detected in one sample collected from the MFC Industrial Waste Ditch with an activity level slightly above the instrument MDA and the MCL. No other 2005 samples from the MFC Industrial Waste Ditch showed detectable levels of Ra-226 above the MCLs. In addition, no other radionuclides were detected above MCLs in the 2005 MFC Industrial Waste Ditch samples. It is possible that the one time detection was an anomaly associated with the analysis.

In one sample collected from the effluent to the TAN/TSF STF Disposal Pond, Sr-90 exceeded the MCL of $8 \mathrm{pCi} / \mathrm{L}$. The activity level in this sample was $14.4 \mathrm{pCi} / \mathrm{L}$. Subsequent samples collected in 2005 showed Sr-90 levels below the MCL. In the past, Sr-90 levels above the MCL have occasionally been detected in the effluent to the TAN/TSF STF Disposal Pond. To support continued discharge to the disposal pond, an ICS has been implemented. The ICS is required to be updated and resubmitted every two years. The ICS was resubmitted in April 2005. The ICS is similar to a BAT plan in that it takes into account alternative treatment or disposal options. It was concluded in the ICS that continued use of the TAN/TSF STF Disposal Pond was the best alternative.

Based on the review of the information discussed in this report, it has been concluded that both BEA and CWI are in compliance with the BAT requirements in DOE Order 5400.5. 


\section{REFERENCES}

ANL-W, 2004, “Argonne National Laboratory-West Environmental Monitoring Program Plan,” W7500-0712-ES-00, January 2004.

DOE O 5400.5, Change 2 "Radiation Protection of the Public and the Environment," U. S. Department of Energy, January 7, 1993.

McNeel, K., BBWI, to R. M. Kauffman, DOE-ID, April 28, 2005, "Interim Control Strategy for the Test Area North/Technical Support Facility Sewage Disposal Pond Two-Year Update," CCN 55614.

PLN-932, "Management Plan and Implementation of Best Available Technology per DOE Order 5400.5 for Disposal of Wastewater," Rev. 1, June 8, 2006.

PLN-8104, "Management Plan and Implementation of Best Available Technology per DOE Order 5400.5 for Disposal of Wastewater," Rev. 0, July 18, 2006. 